\title{
White Blackbirds at Regina
}

\section{by Joyce Dew and Dorene Shuba, Saskatchewan Museum of Natural History}

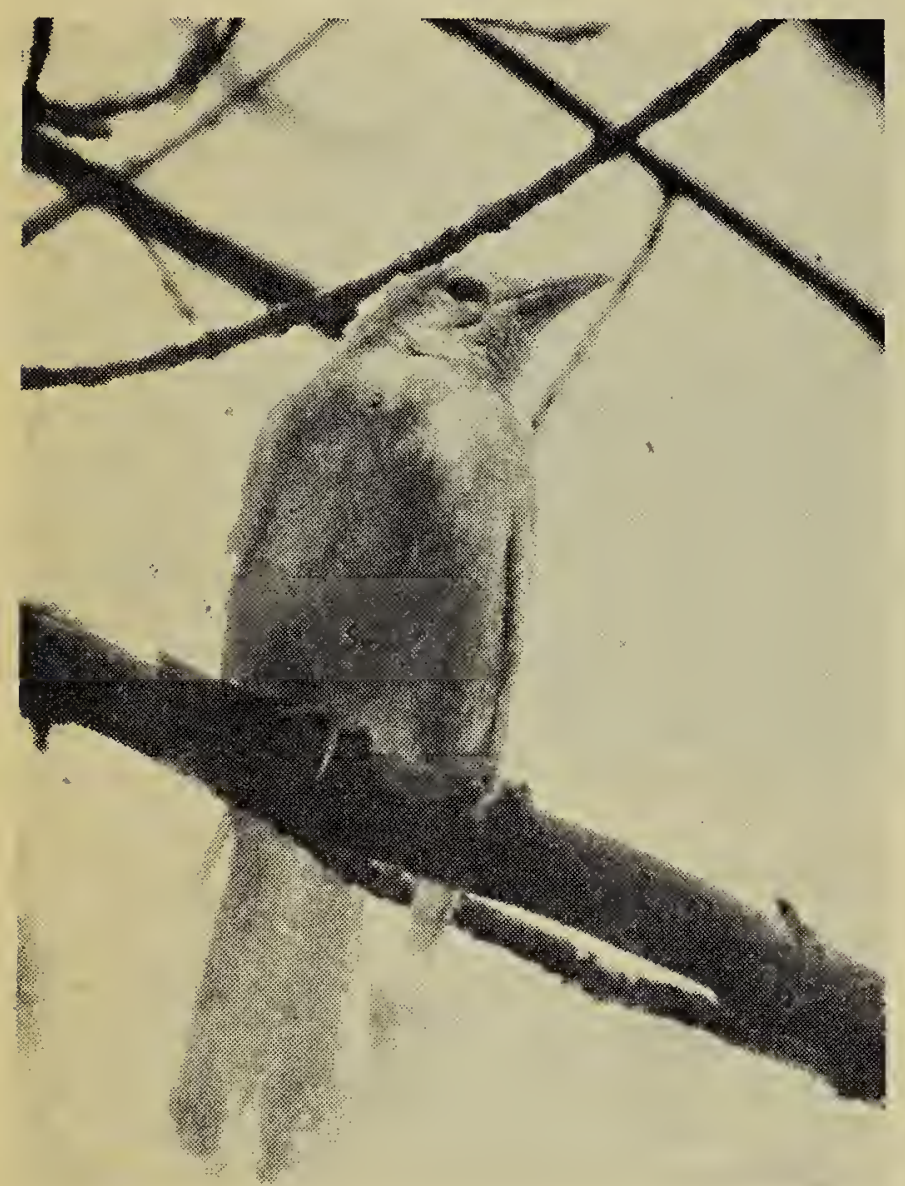

Photo by F. W. Lahrman Albino Grackle

The past summer proved to be an exciting one at the Museum. There was the Queen's visit and the A.O.U. convention, and then in the midst of it all one or more white blackbirds appeared on the scene. Although this event may appear a minor incident compared to the Queen's visit and the A.O.U., it was quite exciting to have the phone ring again and again and hear someone say, "I've just seen a pure white bird!" Mrs. Dorene Shuba, who received most of these phone calls at the Museum, also made several recorded observations of her own on a white juvenile Common Grackle (Quiscalus quiscula), which bird was undoubtedly the basis for many of the phone calls. She also kept the rest of us informed as to its whereabouts. Throughout the summer various reports of "white blackbirds" were received. Two reports were re- ceived in July of an albino "cowbird" and a white blackbird with some brown on it. The bird observed mast frequently throughout the summer was the albino grackle which Mrs. Shuba watched. This bird appeared to be pure white with pink eyes and pink feet. It was photographed in color by Miss Ethel Peart of the Regina Natural History Society, and Fred Lahrman of the Museum staff.

The first report came on June 25 from Leyton Robinson of 2624 Angus Blvd., when he reported an immature albino grackle just learning to fly. As was usually the case, the bird was identified by its association with other grackles. At that time its range included three adjacent yards. Then, on June 30 , several members of the Museum staff saw an albino grackle on the lawn behind the Museum. It was in company with several other grackles and was being fed by one of them. We approached to within four feet of it before it flew away. On July 3 the bird was again seen feeding on the ground in the same area. On July 6 it was seen flying in Wascana Park and while in flight was attacked by another grackle. The attack was in the form of vicious pecks at the albino; which

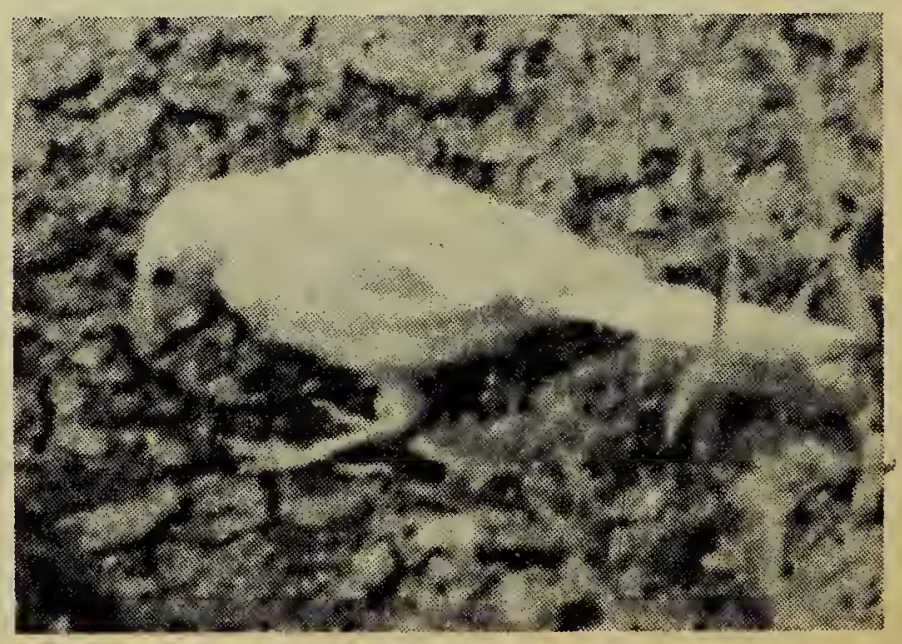

Albino Grackle, photographed by Ethel Peart, July, 1959 
dropped from one to two feet in the air, then flew unevenly for a short distance before gaining control of its flight. It flew away with the other grackle still in pursuit.

A "white blackbird" was reported on July 10 from 23 Block Cornwall, and on July 14 from 23 block McIntyre. On July 15 it was seen by five persons off and on throughout the day. Mrs. Shuba saw the albino being led to the curb by another grackle to drink water. She also saw it being fed. Once, as Mrs. Shuba approached it, it flew into a tree and watched her for a few moments; when she tried to get closer it flew head on into a tree trunk. This seemed to frighten the bird and it then flew into the verandah wall as well. It fluttered about in the air for a few minutes and then rested on the lawn. Later the same day it was seen feeding itself on insects on the branch it was sitting on. At noon it was photographed by Fred Lahrman and later in the day it was again seen feeding itself. At this time it was pecked by another bird and it then moved a short distance away.

An undated observation from 23 block Smith stated that the bird was seen drinking water at a bird bath. It was noted that other birds drinking at the same time soaked bread in the bath before eating it (a common behaviour of grackles) but the albino did not.

Miss Peart took her photo of the albino on 37 block Victoria in July. Other reports came during the first week of September from 21 block King, 22 block Queen, 21 block Princess, and the R.C.M.P. barracks, and Wascana Park. Several of these reports mentioned that the bird was being "picked on" by other blackbirds.

Don Martin, 20 block Argyle, photographed and observed an albino grackle for several weeks during the latter part of September at which time he was putting out food for it. Other "blackbirds" would chase i.t away when it came to feed or if they wanted to feed.

On September 28, a sick albino Common Grackle was brought into the Museum. It had been captured on 27 block Retallack St., and died soon after being brought to the Museum. This albino (which had grey eyes and feet but otherwise appeared to ba the same bird as the one we watched) has now taken its place in the study collection at the Museum.

Note: Although the literature is reple:e with other reports of albinistic birds, very few give any mention of their behaviour. The observa. tions supplied in this note afford additional information on the relationship of an albino to its fellows; reports of the bird being attacked by other grackles are in line with observations reported for a few other species (see, for example, the summary in: Nero, R. W., 1954. Plumage aberrations of the Redwing (A gelaius phoeniceuse). Auk, 71: 137-155. As can be expected with albinos which lack pigment in their irises, this bird appeared to have weak vision. Since it seems likely that the albino grackle which was reported on June 25 was the same as the one preserved as a specimen on September 28, this report also provides infermation on the survival period of an albino grackle (four months). The study skin (S.M.N.H., No. 7221) is rather interesting; according to the preparator, Ralph Ostotoroff, the bird was a female and it had pale grey irises and feet. It is entirely possible that there had been some increase in pigmentaiion in these areas, changing their color from pink to grey. Its bill was nearly white. It can be classified as a nearly complete total albino. The tail fathers are very much worn but ctherwise the plumage appears normal. At first glance it seems to be entirely pure white, but upon close inspection one can see a faint tinge of cream (or very pale brown) colour on the head and throat, more or less covering the area which on a normal female is iridescent blue and purple (much less than in the male). This "colour" is most pronounced on the top of the heard and in a band across the upper chest, corresponding to the margin of the iridescent area in which a normal bird is most highly "coloured." The "colour" is also evident on the inner webs of the tail feathers, again corresponding to an area in which there is ncrmally an iridescent colour effect. Iridescent colours are thought to be mainly produced by mechanical refraction of light, although underlying pigments are necessary to help produce the effect. The apparent remaining "colour" on this grackle may be due to the effect of refraction of Fight with very little or no underlying pigment; I was unable to deteot any pigment in a gross miscroscopic examination of these feathers. This illustraces one of the values of albino specimens-frequently they provide clues to understanding plumage patterns and their control. The extensive analysis of aberrant Redwinged Blackbirds (above reference) permitted several deductions, including the existence of red pigment on the head and throat of adult males, which is normally concealed by black. Hence white Redwinged Blackbirds are normally redheaded! This study also showed a high preponderance of albinism in this species: "96.4 per cent showed some deviation from the wholly dark plumage. . . ."

It is hoped that publication of this note will encourage others to make recorded observations of free-living albinos and to collect such specimens when and where feasible.-R. W. Nero. 